\title{
Edukasi Metode Kontrasepsi Jangka Panjang di Puskesmas Pakuan Baru Kota Jambi
}

\author{
Ria Febrina \\ Program Studi Sarjana Kebidanan dan Pendidikan Profesi Bidan STIKes Baiturrahim Jambi \\ Email:febrinaria2002@gmail.com
}

Submitted : 13/12/2020

Accepted: 16/106/2021

Published: 19/11/2021

\begin{abstract}
Indonesia is currently experiencing population problems, one of which is the population explosion or the continued significant increase in population volume in Indonesia, on the other hand the population distribution is uneven. Based on a population survey in 2010, Indonesia's population was 237.6 million with a population growth rate of around $1.49 \%$. If the government does not succeed in reducing population growth, it is predicted that Indonesia's population in 2060 will reach 475 million - 500 million. One of the government's efforts to control the rate of population growth is through the implementation of the Family Planning (KB) program for Fertile Age Couples (PUS) with the use of contraception. The use of long-term contraceptive methods (MKJP) is still very low, the total of active family planning participants, only $17.45 \%$ of them use MKJP KB. Meanwhile, $81.23 \%$ were non use of long-term contraceptive methods users and $1.32 \%$ used traditional family planning. Public health center of Pakuan Baru in 2018 there were no active family planning participants who used long-term contraceptive methods.Therefore, it is necessary to provide education to increase knowledge of fertile age woman (PUS) about MKJP and increase the coverage of long-term contraceptive methods. Implementation time in Nopember2019-Januari 2020. The targets are women of childbearing age at the public health center of Pakuan Baru. Community service methods include survey and lecture approaches. The results obtained were that fertile age woman was able to understand about long-term contraceptive methods and willing to use long-term contraceptive methods. It is recommended that the public health center maintain the extension program related to long-term contraceptive methods that has been provided.
\end{abstract}

Keywords : family planning, fertile age couple, fertile age woman. long-term contraceptive methods

\begin{abstract}
Abstrak
Indonesia saat ini sedang mengalami problem kependudukan, salah satu diantaranya adalah ledakan penduduk atau terus meningkatnya volume penduduk di Indonesia yang signifikan, dilain pihak jumlah penyebaran penduduk tidak merata. Berdasarkan survey penduduk tahun 2010 jumlah penduduk Indonesia sebesar 237,6 juta jiwa dengan tingkat laju pertumbuhan penduduk sekitar $1,49 \%$. Jika pemerintah tidak berhasil menekan angka pertumbuhan penduduk maka diprediksi jumlah penduduk Indonesia pada tahun 2060 mencapai 475 juta - 500 juta. Salah satu upaya pemerintah untuk mengendalikan laju pertumbuhan penduduk adalah melalui pelaksanaan program Keluarga Berencana (KB) bagi Pasangan Usia Subur (PUS) dengan pemakaian kontrasepsi. Penggunaan metode kontrasepsi jangka panjang (MKJP) masih sangat rendah, dari keseluruhan jumlah peserta KB aktif, hanya 17,45\% diantaranya yang menggunakan KB MKJP. Sedangkan 81,23 \% lainnya pengguna KB non MKJP dan 1,32\% menggunakan KB tradisional. Puskesmas Pakuan Baru pada tahun 2018 tidak ada peserta aktif KB yang menggunakan MKJP. Maka dari itu diperlukan pemberian edukasi untuk meningkatkan pengetahuan PUS tentang MKJP dan meningkatkan cakupan MKJP. Waktu pelaksanaan pada bulan Nopember 2019 s/d Januari 2020. Sasaran adalah ibu wanita usia subur di Puskesmas Pakuan Baru. Metode pengabdian masyarakat meliputi pendekatan survey dan ceramah. Hasil yang diperoleh adalah WUS mampu memahami mengenai MKJP dan mau menggunakan MKJP. Disarankan kepada pihak Puskesmas untuk mempertahankan program penyuluhan terkait MKJP yang sudah diberikan.
\end{abstract}

Kata Kunci : keluarga berencana, MKJP, PUS, WUS 


\section{PENDAHULUAN}

Salah satu persoalan besar yang dihadapi dunia adalah masalah kependudukan. Jumlah penduduk dunia semakin menunjukan angka yang terus bertambah, dan telah menimbulkan masalah sosial seperti permasalahan laju pertumbuhan penduduk, kebutuhan sandang dan pangan serta meningkatnya pengangguran, kemiskinan, dan tingkat kriminalitas.

Jumlah penduduk Indonesia saat ini sudah sangat banyak diperkirakan akan terus bertambah karena pertumbuhan jumlah penduduk yang tinggi. Hal ini disebabkan oleh angka kelahiran lebih tinggi dibandingkan dengan angka kematian.Untuk itu diperlukan upaya dan langkah konkrit guna menurunkan laju pertumbuhan penduduk melalui berbagai program baik dari aspek kualitas maupun kuantitas (Kementrian Koordinator Bidang Kesejahteraan Rakyat, 2013).

Salah satu upaya pemerintah untuk mengendalikan laju pertumbuhan penduduk adalah merencanakan dan mengatur keluarga melalui pelaksanaan program Keluarga Berencana (KB). Program KB bertujuan bagaimana mengatur jarak atau membatasi kelahiran anak (Azizah, 2019).

Penggunaan kontrasepsi merupakan salah satu upaya dalam program keluarga berencana untuk pengendalian fertilitas atau menekan pertumbuhan penduduk yang paling efektif. Di dalam pelaksanaannya diupayakan agar semua metoda atau alat kontrasepsi yang disediakan dan ditawarkan kepada masyarakat memberikan manfaat optimal dengan meminimalkan efek samping maupun keluhan yang ditimbulkan (Asih dan Oesman, 2009).

Menurut efektifitas lamanya metode kontrasepsi ada dua macam yaitu Metode Kontrasepsi Jangka Panjang (MKJP) dan nonMKJP. Metoda Kontrasepsi Jangka Panjang adalah kontrasepsi yang dapat dipakai dalam jangka waktu lama, lebih dari dua tahun, efektif dan efisien untuk tujuan pemakaian menjarangkan kelahiran lebih dari 3 tahun atau mengakhiri kehamilan pada pasangan yang sudah tidak ingin tambah anak lagi. Jenis metode yang termasuk dalam kelompok ini adalah metoda kontrasepsi mantap (pria dan wanita), implant, dan Intra Uterine Device (IUD) (BKKBN, 2015).

Penggunaan MKJP masih sangat rendah, dari keseluruhan jumlah peserta $\mathrm{KB}$ aktif, hanya $17,45 \%$ diantaranya yang menggunakan KB MKJP. Sedangkan 81,23 $\%$ lainnya pengguna $\mathrm{KB}$ non MKJP dan $1,32 \%$ menggunakan $\mathrm{KB}$ tradisional (Kemenkes, 2017). Realisasi pencapaian peserta KB baru MKJP dari 33 provinsi di Indonesia tertinggi terdapat pada provinsi Nusa Tenggara Timur sebanyak $10.0 \%$ yang diikuti oleh Maluku Utara sebanyak $7.2 \%$ dan Provinsi Jambi hanya 1,9\%.

Peserta KB aktif MKJP di Provinsi Jambi untuk pengguna metode IUD tertinggi terdapat di Kabupaten Kerinci sebesar 59,92 \% diikuti dengan Kota Jambi sebesar 52,13\%, metode implant terdapat pada Kabupaten Sarolangun sebesar $89.00 \%$ dan terendah di Kota Jambi sebesar $35.70 \%$, metode WOW tertinggi terdapat di Kota Jambi sebesar $11.06 \%$, dan metode MOP tertinggi terdapat di Kabupaten Tanjung Jabung Timur sebesar $8.78 \%$ (BKKBN, 2016).

Berdasarkan data yang diperoleh dari Dinas Kesehatan Kota Jambi tahun 2018 pada pemasangan MKJP jumlah peserta KB aktif metode kontrasepsi cara modern yaitu AKDR sebanyak 2.032, implant sebanyak 1.252 orang, MOW sebanyak 542 orang, MOP sebanyak 16 orang (Dinkes Kota Jambi, 2018). Berdasarkan data dari 20 Puskesmas yang ada di Kota Jambi tahun 2018, Puskesmas Pakuan Baru tidak ada peserta aktif KB yang menggunakan MKJP.

Faktor-faktor yang berhubungan dengan rendahnya minat ibu terhadap penggunaan MKJP menurut hasil penelitian Sari, Eminur dan Evi (2017) adalah usia, jumlah anak, pendapatan, pengetahuan, 
paparan sumber informasi dan persepsi individu.

Salah satu faktor yang mempengaruhi pemakaian kontrasepsi adalah pengetahuan. Dengan keterbatasan pengetahuan akan mempengaruhi pemilihan ibu pada pada metode kontrasepsi. Pengetahuan yang benar tentang program $\mathrm{KB}$ termasuk tentang berbagai jenis kontrasepsi akan mempertinggi keikutsertaan masyarakat dalam program $\mathrm{KB}$

merupakan domain yang sangat penting untuk terbentuknya tindakan seseorang. Pengetahuan sangat erat hubungannya dengan pendidikan dimana seseorang dengan pendidikan tinggi, maka orang tersebut akan semakin luas pengetahuannya (Notoatmodjo,2007).

Berdasarkan alasan diatas maka perlu diberikannya edukasi mengenai kontrasepsi khusunya MKJP sebagai upaya untuk meningkatkan pengetahuan serta penggunaan kontrasepsi khusunya MKJP.

\section{TARGET DAN LUARAN}

1. Target

Target dalam kegiatan pengabdian kepada masyarakat ini adalah wanita usia subur (WUS) yang sudah menikah.

2. Luaran

Adapun luaran kegiatan pengabdian masyarakat ini selain publikasi pada jurnal ilmiah yaitu Pemahaman wus tentang MKJP Serta peningkatan capaian penggunaan MKJP.

\section{METODE PELAKSANAAN}

Kegiatan pengabdian kepada masyarakat dilaksanakan pada bulan Nopember 2019- Januari 2020 dengan sasaran kegiatan adalah remaja putri berjumlah 20 orang. Tahapan kegiatan pengabdian kepada masyarakat meliputi:

Persiapan

1. Sosialisasi: pertemuan dengan pihak puskesmas Pakuan Baru.

2. Mengidentifikasi masalah.
3. Permusuan solusi : menyampaikan rencana kegiatan kepada pihak Puskesmas dengan mengurus surat izin melakukan kegiatan pengabdian kepada masyarakat.

Pelaksanaan

1. Melakukan pretest (menggali pemahaman WUS tentang MKJP)

2. Memberikan konseling tentang MKJP (pengertian, jenis MKJP, keuntungan dan kerugian MKJP, indikasi dan kontraindikasi MKJP.

3. Monitoring dan Evaluasi.

\section{HASIL DAN PEMBAHASAN}

Kegiatan pengabdian masyarakat ini bertujuan agar WUS yang sudah menikah memahami tentang MKJP. Pada pengabdian ini dilakukan pemberian konseling kepada WUS yang sudah menikah mengenai MKJP. Kegiatan konseling berlangsung kurang lebih 5-10 menit per orang dan terlaksana dengan tertib dan lancar serta mendapat antusias yang baik dari para peserta dan pihak puskesmas. Kegiatan yang dilakukan adalah memberikan edukasi kesehatan berupa konseling MKJP meliputi pengertian, jenis MKJP, keuntungan dan kerugian MKJP.

Pendidikan kesehatan merupakan suatu proses untuk menyadarkan, meningkatkan pengetahuan dan merubah perilaku masyarakat tentang kesehatan. Pendidikan kesehatan bertujuan agar masyarakat menyadari dan mengetahui cara memelihara kesehatan, menghindari atau mencegah dari hal-hal yang merugikan kesehatan serta bagaimana mencari pengobatan yang tepat (Notoatmojo, 2007). Pemberian konseling diharapkan dapat meningkatkan pengetahuan WUS yang sudah menikah tentang MKJP serta keuntungan dan kerugian MKJP 


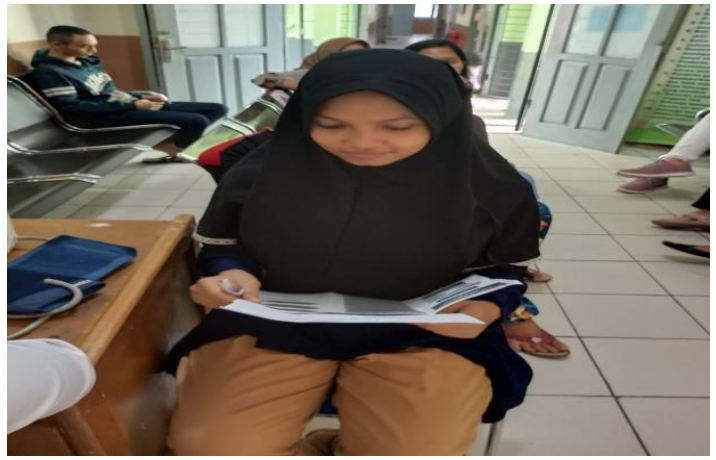

Gambar 1. Konseling kesehatan

Sebagian besar (95\%) pasien pascapersalinan ingin menunda kehamilan berikutnya paling sedikit dua tahun lagi atau tidak ingin menambah anak lagi. Metode yang dapat digunakan meliputi amenore laktasi (MAL), AKDR, metode operasi wanita (MOW), dan metode $\mathrm{KB}$ hormonal (implant) yang tidak mengganggu ASI, suntik (hanya mengandung progestin), minipil (hanya mengandung progestin).

Kontrasepsi yang menjadi pilihan ibu pascapersalinan adalah metode kontrasepsi jangka panjang. Metode tersebut dapat digunakan jangka panjang sehingga menunda masa kehamilan dan menghindari kehamilan yang tidak diinginkan. Namun saat ini, proporsi masyarakat yang menggunakan kontrasepsi jangka panjang mengalami penurunan antara lain disebabkan oleh KIE belum mampu menyampaikan informasi kontrasepsi jangka panjang dan konseling yang belum sesuai dengan prosedur.

Masih rendahnya akseptor KB yang menggunakan MKJP perlu diberikan pendidikan kesehatan untuk meningkatkan pengetahuan dan memperbaiki informasi yang salah terkait MKJP. Hal ini sesuai dengan teori Notoatmodjo (2010), yang mengatakan bahwa pendidikan kesehatan ditujukan untuk menggugah kesadaran, memberikan atau meningkatkan pengetahuan masyarakat tentang pemeliharaan dan peningkatan kesehatan baik bagi dirinya sendiri, keluarganya maupun masyarakatnya.

Hasil penelitian Resy \& Destyna (2019) menyatakan bahwa ada pengaruh pemilihan materi dan media konseling yang baik, serta metode yang tepat terhadap pemilihan MKJP. Konseling yang dapat mengubah perilaku pemilihan kontrasepsi diharapkan sesuai dengan prinsip konseling. Konseling menerapkan komunikasi yang diawali dengan interaksi saling percaya pada klien. Nada suara rendah digunakan, kritik dan penilaian dihindari dan dengar dan cermati perasaan atau pesan dibalik ucapan, dan hormati kerahasiaan klien. Topik pada konseling harus logis dan sesuai urutan sehingga keselurahan masalah mampu diidentifikasi.

\section{KESIMPULAN DAN SARAN}

\section{Kesimpulan}

Pelaksanaan pengabdian kepada WUS di Puskesmas Pakuan Baru berjalan dengan baik. WUS yang sudah menikah memahami tentang MKJP dan ada keinginan menggunakan MKPJ untuk kontrasepsi yang digunakan.

\section{Saran}

Diharapkan pihak puskesmas dapat secara rutin memberikan pendidikan kesehatan terkait MKJP serta sebaiknya dalam memberikan konseling meningkatkan kualitas materi, media dan metode yang digunakan agar WUS dapat menjadikan MKJP sebagai metode kontrasepsi yang digunaka.

\section{UCAPAN TERIMAKASIH}

Ucapan terimakasih kami sampaikan kepada Sekolah Tinggi Ilmu Kesehatan Baiturrahim Jambi yang telah memfasilitasi kegiatan ini dan tak lupa kepada semua pihak yang telah membantu kegiatan kepada masyarakat ini.

\section{DAFTAR PUSTAKA}

Asih, Oesman. 2009. Faktor-faktor yang Mempengaruhi Pemakaian Kontrasepsi Jangka Panjang (MKJP), Analisa Lanjut SDKI 2007. BKKBN. Jakarta. 
Azizah, Raffy Nur. 2019. Peran Program $K B$ dalam pengendalian pertumbuhan penduduk: Studi kasus di Desa Cinta Kecamatan Karangtengah Kabupaten Garut. UIN Sunan Gunung Djati Bandung.

BKKBN. 2015. Keluarga Berencana dan Kontrasepsi. Cetakan ke-5. Jakarta: Pustaka Sinar Harapan.

BKKBN. 2016. Pelayanan Kontrasepsi. BKKBN. Jakarta

Dinas Kesehatan Kota Jambi. 2018. Profil Kesehatan Kota Jambi. Dinas Kesehatan Kota Jambi. Jambi.

Kementerian Koordinator Bidang Kesejahteraan Rakyat. (2013).
Mulianda, RT \& Gultom, DY. 2019. Pengaruh Pemberian Konseling KB terhadap Pemilihan Kontrasepsi Jangka Panjang (MKJP) di Kelurahan Belawan Bahagia Tahun 2018. Jurnal Ilmiah Kebidanan IMELDA. 5(2).

Sari, Eminur dan Evi. 2017. Faktor-faktor yang Berhubungan dengan Rendahnya Minat Ibu terhadap Penggunaan Metode Kontrasepsi Jangka Panjang di BPS Sri Romdhati Semin Gunung Kidul. Jurnal Universitas Aisyiyah Yogyakarta.

http://digilib.unisayogya.ac.id/id/eprint/ 2404 